\title{
Appendicular abscess: as a masquerader and pheochromocytoma as an incidentaloma in a 12 year old male child
}

\author{
Jayasurya Suresh ${ }^{1 *}$, John Mathew P.ㄹ, Nidheesh Chandran R. ${ }^{3}$
}

\author{
${ }^{1}$ Department of Paediatrics, Providence hospital, Alappuzha, Kerala, India \\ ${ }^{2}$ Department of General and Laparoscopic Surgery, Providence hospital, Alappuzha, Kerala, India \\ ${ }^{3}$ Department of General Medicine, Mysore medical college, Karnataka, India
}

Received: 08 July2020

Accepted: 07 August 2020

\author{
*Correspondence: \\ Dr. Jayasurya Suresh, \\ E-mail: drjayasuryasuresh@gmail.com
}

Copyright: $@$ the author(s), publisher and licensee Medip Academy. This is an open-access article distributed under the terms of the Creative Commons Attribution Non-Commercial License, which permits unrestricted non-commercial use, distribution, and reproduction in any medium, provided the original work is properly cited.

\begin{abstract}
A 12 year old boy presented initially with symptoms suggestive of urinary tract infection (UTI). Later, it turned out to be acute appendicitis with appendicular abscess. Pre-operative investigations revealed co-presentation of pheochromocytoma. Although this child was having no symptoms of pheochromocytoma, the presentation of phaechromocytoma with appendicular abscess needs to be dealt with extreme vigil as pheochromocytoma can result in severe sympathetic outburst storm. Laparoscopic appendicectomy was done and the child was discharged after complete recovery.
\end{abstract}

Keywords: Appendicitis, Appendicular abscess, Pheochromocytoma, Incidentaloma

\section{INTRODUCTION}

Appendicitis is a common surgical emergency in children. With a wide range of underlying causes and various clinical presentations, timely diagnosis can sometimes be a diagnostic challenge unless the child presents with classical symptoms of appendicitis. Appendicular abscess and appendicular perforation are likely complications of appendicitis. ${ }^{1}$ Ultrasound abdomen is an important diagnostic tool in the diagnosis of appendicitis. ${ }^{2}$ There are many instances for a diagnostic delay of appendicitis in children as there can be variegate and vague presentations and there are many instances of functional abdominal pain. Hence abdominal pain in children should be viewed with caution by the paediatrician and repeated physical examinations should be done and a surgical opinion should be taken when there is a diagnostic dilemma. ${ }^{3}$

Pheochromocytoma is a rare tumor of adrenal medulla, which is classified as a catecholamine producing neuro endocrine tumor. They can also be present anywhere in the abdomen, including pancreas. They can lead to a catastrophic presentation due to increased stimulation of the sympathetic system. ${ }^{4}$

There have been few instances where pheochromocytoma was found as an incidentaloma in children with pheochromocytoma, although such incidences are very rare. Such presentations can cause severe complications during intra-op including anaesthetic complications. ${ }^{5}$ There have been also instances where appendicectomy surgery was cancelled and the patient was managed conservatively with antibiotics and antihypertensive medications when a presentation of appendicitis with undiagnosed pheochromocytoma was detected. ${ }^{6}$

\section{CASE REPORT}

A 12 year old boy presented to pediatrics OPD with symptoms suggestive of pain during micturition, fever, and vague abdominal pain. Urine microscopy showed plenty of pus cells and urine culture was sent. He was asked to follow up after two days. He was given a course of antibiotics but symptoms persisted. The child developed 
right inguinal pain and on examination right iliac fossa tenderness, guarding and rigidity were found. Hence acute appendicitis was suspected. Pre-operative investigations were done. The ultrasonography (USG) of abdomen showed appendicular abscess and incidental pheochromocytoma. The child did not have any symptoms of pheochromocytoma. Pheochromocytoma can cause severe intra operative complications like hypertensive crisis and uncontrolled tachycardia. Hence contrast enhanced computed tomography (CECT) of abdomen was done for a better picture (Figure 1). Diagnosis of appendicular abscess with fecalith and incidental pheochromocytoma on the head of pancreas was confirmed. As it was a surgical emergency and the child was sick, laparoscopic appendicectomy was done (Figure 2). Purulent cavity with gangrenous sloughed out appendix and fecalith were seen. Hemostasis secured. Right flank drain placed in the abscess cavity. There was no intraoperative sympathetic crisis. The child was put on vancomycin and meropenam antibiotics for 10 days. In due course of hospital stay, the child symptomatically improved and hence discharged.

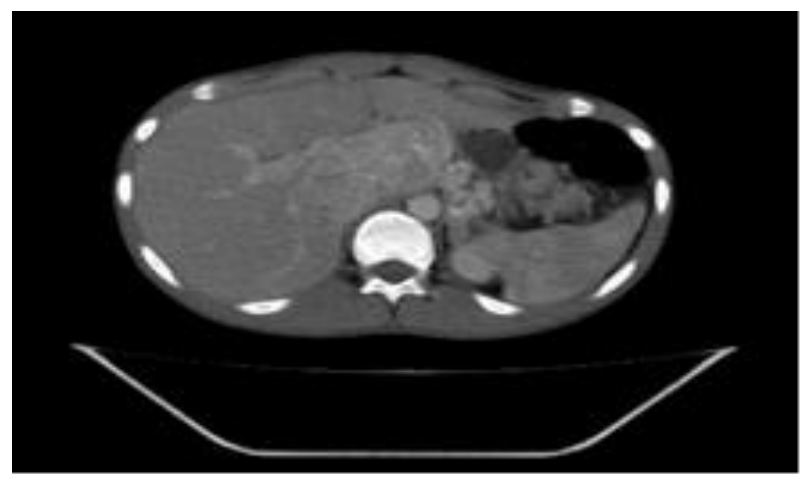

Figure 1: CECT abdomen - appendicular abscess and the incidentaloma on the head of pancreas.

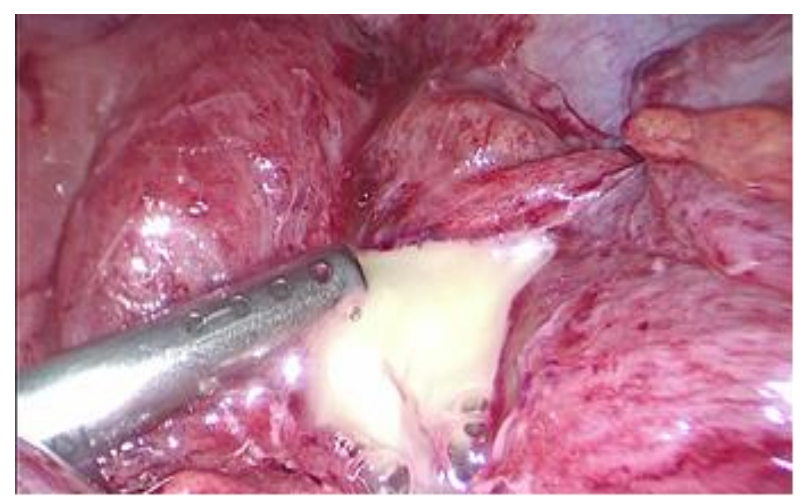

Figure 2: Laparoscopic intra-operative picture of appendicular abscess.

\section{DISCUSSION}

Appendicitis is one of the common surgical emergencies in children. It has a wide range of clinical presentations ranging from anorexia, fever, vomiting and diarrhoea to the typical symptom of right iliac fossa tenderness. ${ }^{7}$ Hence, the paediatrician should execute extreme caution while examining a child with vague symptoms and abdominal pain so that an underlying acute appendicitis is not missed. A surgical opinion should be taken in case of doubt. The index case presented with typical urinary symptoms with plenty of pus cells in routine urine examination. There was no right iliac fossa tenderness or guarding or rigidity at the presentation but developed after 2 days when the child was examined during the follow-up visit. The child also had tachycardia. Here during preoperative USG abdomen, a lesion suggestive of pheochromocytoma on the head of pancreas was detected, which was confirmed with CECT abdomen. Laparoscopic surgery for appendicular abscess was done with extreme caution, preventing any exposure to phaechoromocytoma because it can lead to severe intra op sympathetic crisis and uncontrolled hypertension if the surgical field is exposed to phaechromocytoma. It is a rare co-presentation that requires the team management with intra-op preparedness for a sympathetic outburst. Pheochromocytoma can also present as an asymptomatic lesion while in most children, the presentation is hypertension. ${ }^{7}$

\section{CONCLUSION}

Pheochromocytoma can present as an incidentaloma in a surgical emergency in an asymptomatic child. Preparedness for a clinical challenge should occur when a previously undiagnosed, not treated, pheochromocytoma presents in a surgical emergency. A multidisciplinary team involving anaesthetists, experienced surgical team, and intensive paediatric unit is mandatory before taking up a case of acute appendicitis with incidental detection of pheochromocytoma.

\section{Funding: No funding sources Conflict of interest: None declared Ethical approval: Not required}

\section{REFERENCES}

1. Bhangu A, Soreide K, Di Saverio S, Assarson JH, Drake FT. Acute appendicitis: modern understanding of pathogenesis, diagnosis, and management. Lancet. 2015;386:1278-87.

2. Hamid MA, Afroz R, Ahmed UN, Bawani A, Khan D, Shahab R, Salim A. The importance of visualization of appendix on abdominal ultrasound for the diagnosis of appendicitis in children: a quality assessment review. World J Emerg Med. 2020;11:140-4.

3. Kambouri K, Aggelidou M, Deftereos S, Tsalkidis A, Vaos G, Pitiakoudis M. What are the risk factors responsible for the delay in diagnosis of acute appendicitis in children? Eleven year research from a single institution. Folia Med. 2019;51:389-96.

4. Nolting $\mathrm{S}$, Ullrich $\mathrm{M}$, Pietzsch J, Ziegler CG, Eisenhofer G, Pacak K. Current management of pheochromocytoma/paraganglioma: a guide for the 
practicing clinician in the era of precision medicine. Cancers. 2019;11:10

5. Tariq SM, Haider SA, Siddiqui AT, Hasan M. Pheochromocytoma- an incidental finding in a child with acute appendicitis. J Pak Med Assoc. 2018;68:1854-8.

6. Tarant NS, Dacanay RG, Mecklenburg BW, Birmingham SD, Lujan E, Green R. Acute appendicitis in a patient with undiagnosed pheochromocytoma. Anesth Analg. 2006;102:642-3.

7. Song CW, Kang JW, Kim JY. Different clinical features and lower scores in clinical scoring systems for appendicitis in preschool children: comparison with school age onset. Paediatr Gastroenterol Hepatol Nutr. 2018;21:51-8.

Cite this article as: Suresh J, Mathew JP, Chandran NR. Appendicular abscess: as a masquerader and pheochromocytoma as an incidentaloma in a 12 year old male child. Int Surg J. 2020;7(9):3160-2. 